Abstract PTH-161 Table 1

\begin{tabular}{|c|c|c|c|c|c|c|c|c|c|}
\hline Group & $\begin{array}{l}\text { Known } \\
\text { IBD (\%) }\end{array}$ & $\begin{array}{c}\text { New } \\
\text { IBD (\%) }\end{array}$ & PUD (\%) & NSI (\%) & Cancer (\%) & $\begin{array}{c}\text { CRA } \\
(\%)\end{array}$ & Coeliac (\%) & Unknown (\%) & Other (\%) \\
\hline Age $<55+$ FCP 60-100 $(n=15)$ & $\begin{array}{c}\text { AB4 } \\
(26.7)\end{array}$ & $\begin{array}{l}A B 0 \\
(0.0)\end{array}$ & $\begin{array}{l}\text { ABO } \\
(0.0)\end{array}$ & $\begin{array}{c}\text { AB2 } \\
(13.3)\end{array}$ & $\begin{array}{l}\text { ABO } \\
(0.0)\end{array}$ & $\begin{array}{l}A B 0 \\
(0.0)\end{array}$ & $\begin{array}{l}\text { ABO } \\
(0.0)\end{array}$ & $\begin{array}{l}A B 1 \\
(6.7)\end{array}$ & $\begin{array}{c}\text { AB8 } \\
(53.3)\end{array}$ \\
\hline Age $<55+$ FCP $>100(n=68)$ & $\begin{array}{l}\text { AB39 } \\
(57.4)\end{array}$ & $\begin{array}{l}\text { AB6 } \\
(8.8)\end{array}$ & $\begin{array}{l}\text { AB2 } \\
(2.9)\end{array}$ & $\begin{array}{l}\text { AB3 } \\
(4.4)\end{array}$ & $\begin{array}{l}\text { ABO } \\
(0.0)\end{array}$ & $\begin{array}{l}\text { ABO } \\
(0.0)\end{array}$ & $\begin{array}{l}\text { AB1 } \\
(1.5)\end{array}$ & $\begin{array}{l}\text { AB4 } \\
(5.9)\end{array}$ & $\begin{array}{l}\text { AB13 } \\
(19.1)\end{array}$ \\
\hline Age $>55+$ FCP 60-100 $(n=11)$ & $\begin{array}{c}\text { AB3 } \\
(27.3)\end{array}$ & $\begin{array}{l}\mathrm{ABO} \\
(0.0)\end{array}$ & $\begin{array}{l}A B 0 \\
(0.0)\end{array}$ & $\begin{array}{l}A B 0 \\
(0.0)\end{array}$ & $\begin{array}{l}A B 0 \\
(0.0)\end{array}$ & $\begin{array}{l}\text { AB1 } \\
(9.1)\end{array}$ & $\begin{array}{l}A B 0 \\
(0.0)\end{array}$ & $\begin{array}{l}\mathrm{ABO} \\
(0.0)\end{array}$ & $\begin{array}{c}A B 7 \\
(63.6)\end{array}$ \\
\hline Age $>55+F C P>100(n=42)$ & $\begin{array}{l}\text { AB22 } \\
(52.3)\end{array}$ & $\begin{array}{l}\mathrm{AB} 2 \\
(4.8)\end{array}$ & $\begin{array}{l}\mathrm{ABO} \\
(0.0)\end{array}$ & $\begin{array}{l}\mathrm{AB} 0 \\
(0.0)\end{array}$ & $\begin{array}{l}\mathrm{AB} 2 \\
(4.8)\end{array}$ & $\begin{array}{l}\mathrm{AB} 2 \\
(4.8)\end{array}$ & $\begin{array}{l}\mathrm{AB} 0 \\
(0.0)\end{array}$ & $\begin{array}{l}\mathrm{AB} 2 \\
(4.8)\end{array}$ & $\begin{array}{l}\mathrm{AB} 12 \\
(28.5)\end{array}$ \\
\hline
\end{tabular}

reviewed in addition to clinic letters to understand clinician interpretation of results when necessary. Patients were categorised by age and FCP result. Outcomes in patients without IBD were categorised as: new IBD, non-specific inflammation/ulceration (NSI), peptic ulcer disease (PUD), cancer, colorectal adenoma (CRA), coeliac disease, other (including irritable bowel syndrome, bile salt malabsorption) or unknown where no additional information was available.

Results 147 positive (of 391, 37.6\%) FCP results were identified. 11 were excluded, as investigations were ongoing. The outcome of investigations per category are summarised in Table 1.

Conclusion The use of FCP is increasing. In our unit, the majority are used for assessment in patients with known IBD. In patients in whom FCP was used to aid diagnosis, those with a result $<100$ had a 'benign' diagnosis following investigation in both age categories suggesting a considered approach in this group may be reasonable.

Disclosure of Interest None Declared.

\section{PTH-162 THE CHALLENGES OF IMPLEMENTING EVIDENCE INTO ENDOSCOPIC PRACTICE: A QUALITATIVE STUDY}

doi:10.1136/gutjnl-2013-304907.649

1."P T Rajasekhar, ${ }^{2} \mathrm{~S}$ Brown, ${ }^{3} \mathrm{C}$ Nixon, ${ }^{4} \mathrm{M}$ Bramble, $5 \mathrm{~J}$ East, ${ }^{6} \mathrm{M}$ Rutter, ${ }^{7} \mathrm{~B}$ Saunders, ${ }^{1} \mathrm{C}$ Rees on behalf of The Quality in Colonoscopy Study Group. 'Gastroenterology, South Tyneside District Hospital, South Shields; '2Evaluation Research Development Unit, Durham University, Stockton-on-Tees; ${ }^{3}$ Department of Social Science, Sunderland University, Sunderland; ${ }^{4}$ School of Medicine and Health Science, Durham University, Stockton-on-Tees; ${ }^{5}$ Gastroenterology, John Radcliffe Hospital, Oxford; ${ }^{6}$ Gastroenterology, University Hospital of North Tees, Stockton-on-Tees; ' Gastroenterology, St Marks Hospital, Harrow, UK

Introduction The Quality Improvement in Colonoscopy (OIC) study was a region wide service improvement study that aimed to improve adenoma detection rate (ADR), and thusly quality in colonoscopy, through implementation of a 'bundle' of measures to routine colonoscopy practise. These were: withdrawal time $\geq 6$ minutes; routine hyoscine butylbromide use; supine position to examine the transverse colon; rectal retroflexion. Each has been shown to improve adenoma detection. The implementation of evidence into clinical practise can be challenging. We performed a qualitative interview study to evaluate factors that influenced implementation of the 'bundle' in the OIC study.

Methods The study took place in 12 units who are members of the Northern Region Endoscopy Group, a research network in the north east of England. The study team held training sessions in each unit to introduce the 'bundle', supported by a nominated local lead colonoscopist and nurse. Posters were supplied for each endoscopy room to aid promotion. Following OIC study completion units and individuals were purposively sampled for the qualitative interview study ensuring a range of units (by size, bundle uptake) were included. Semi-structured interviews were conducted until saturation was reached. Data were evaluated using thematic analysis to code and categorise interviews.
Results 119 colonoscopists participated in the OIC study. Interviews were conducted with 11 participants. 8 were lead colonoscopists, 1 a lead nurse and 3 colonoscopists who weren't leads. Increased emphasis on examination time, increased awareness of $\mathrm{ADR}$ as a quality marker and empowerment of endoscopy nurses to encourage use of quality measures were seen as positive impacts of introducing the 'bundle'. The simple, highly visible posters were also reported as useful in aiding study promotion. Challenges included difficulty in arranging set up meetings and in engaging certain speciality groups.

Conclusion Implementation of evidence into clinical practise can be challenging. During the OIC study, challenges included arranging staff meetings and engaging all team members. Positive outcomes included increased awareness of colonoscopy quality, particularly slower withdrawal times, and empowerment of endoscopy nurses to promote quality measures. We demonstrate that emphasis on timing of meetings and strategies to engage speciality groups should be given consideration when planning implementation of evidence or guidelines into clinical practise.

Disclosure of Interest None Declared.

\section{PTH-163 NURSE LED TELEPHONE CLINICS- THE NHS REVOLUTION IN MAKING}

doi:10.1136/qutinl-2013-304907.650

1."R Shah, ${ }^{2} \mathrm{~L} T$ Tan, ${ }^{3} \mathrm{G}$ Lim. ${ }^{1}$ Gastroenterology, NHS, Farnborough; ${ }^{2}$ Gastroenterology; ${ }^{3}$ NHS, Epsom, UK

Introduction Patients under the care of Gastroenterologists suffer from a wide variety of acute and chronic conditions which often need regular intensive monitoring. This often necessitates frequent outpatient visits and follows up blood tests.

To improve both patient care and efficiency, a telephone clinic led by nurse specialists was instigated.

The patients included those with follow ups of investigations into anaemia, abnormal liver function tests, coeliac disease, inflammatory bowel disease hepatitis $\mathrm{B} / \mathrm{C}$ and irritable bowel disease.

Patients, who required drug monitoring, follow up of blood tests, histology and radiological investigations including flare ups of their inflammatory bowel condition were included.

Methods This initial consultation was in a consultant led clinic following which the results were communicated via the telephone clinic in 4-6 weeks. Depending on the initial results further investigations, treatment or follow up was arranged according to clinical need.

Patients with flares of IBD, follow up of treatment of Hepatitis $\mathrm{B} / \mathrm{C}$ were now directly in contact with nurse led telephone clinics who in turn could give specialist advise and expedite treatment and investigations.

December 2009 were analysed. Similar data from 2005 was used as control ${ }^{\text {st }}$ January 2009 to $31^{\text {st }}$ Data regarding outpatient and telephone clinic activities from 1 . 